\title{
Discounting the future: influence of the economic model
}

\author{
Robert R West
}

\begin{abstract}
Objective - To consider the effect of the economic discount rate on health care policy and the rationale for discounting the collective future of society generally.

Design - A review of the concept of discounting the future vis à vis the present from the points of view of individuals (who pass on) and of societies (that continue) and reconsideration of the application of discounting to typical public health scenarios.

Setting - A public health service, within a basically stable society, which can reasonably anticipate a nearly certain future. Results - Discounting necessarily overvalues the "here and now" compared with the future. While applications of discount rates, typical of those employed in health economic studies in recent years, may seem rational in health care programmes directed at middle aged employed people, they do not for the young and the elderly, important recipients of health care. The consequences of discounting do not accord with the aims and objectives of public health.

Conclusions - The "time preferences" of transient individuals within a stable society do not provide a rational basis for time preference of a stable society collectively. Discounting inevitably encourages "short termism" and hence biases public policy decision making. The neoclassical theory that gave rise to the concept of discounting requires revision.
\end{abstract}

( $\mathcal{F}$ Epidemiol Community Health 1996;50:239-244)

This paper discusses the effect of the economic discount rate on public policy decisions, particularly in health care. Since discounting is employed in most economic analysis and is almost inseparable from economics, any discussion of the rationale, basis, or consequences of discounting also involves some consideration of the foundations, assumptions, and philosophy of economics itself.

\section{History}

Most readers would agree that the economy has a profound impact on our lives, and hence that economics, the study of the economy, is important. In most of the developed world, collective decisions generally seem to be driven by economic considerations and politicians seeking to promote their social policies almost invariably invoke economic issues and resort to economic arguments. Economics or the discussion of economic issues surrounds us and it is second only to sport in the news. It was not always so - the history of economics, or at least of neoclassical economics, is very much the history of paid employment. ${ }^{1}$ Sociology and anthropology are probably better able than economics to describe human activity, behavour, and choice in times before paid employment or in cultures without paid employment.

\section{Science?}

Many, including the Nobel Loreat Committee, seem to classify economics as a science. That being so, it is important to consider what kind of science it is and what stage or phase of development it has reached, because of the effect on society of application of economic knowledge. It is clearly not a science with laws as in physics, equations as in chemistry, or models as in engineering and it is not yet developed to the stage that we may use its laws and equations to build models of society that yield predetermined and desirable outcomes at least not satisfactorily. Historians of science, who describe stages or phases in the development of a science, might classify economics as about the stage of observation and inference, theory and hypothesis testing. Economics is perhaps at a similar stage of development as another young science, epidemiology, which is also predominantly a science of observation and inference. The intellectual challenges of epidemiology are mainly those of drawing inference from observational studies but epidemiology also emphasises the importance of distinguishing between association and causation and recognises the role of experiment as the final arbiter. There are several interesting parallels, like the difficulty of testing hypotheses experimentally for practical or ethical reasons, but there are also important differences, including the continuing debate about the principles underlying discounting. 


\section{Applied science?}

Engineering is the most obviously applied science born out of physics, chemistry, and mathematics. Epidemiology has many applications - in public health, health education, and health services evaluation - and economics has many potential applications in these same areas, because the economy is so central to human wellbeing. In the prevailing economic climate, it has been assumed by many that economics has been promoted to the status of an applied science. Theoretical economists who really understand the nature (and limitations?) of their subject, seem to be greatly outnumbered by "practitioners" who seem less aware of the many necessary steps between theory (based on observation and inference) and a working model that can be offered to planners and policy makers. This is analogous perhaps to the many steps it is necessary to take between hot gas expands (a law of physics) and the modern jet engine. These practitioners or technicians seem to be all too prepared to offer their services to society, and society appears to be all too willing to seek their services ${ }^{2}$; suggesting an almost incredulous belief that the subject is fully understood and a faith in the ability of those who know the formulae to control the economy.

\section{Assumptions}

Since economic analyses usually make (several) assumptions, this discussion of the rationale, basis, and consequences of discounting will adopt that convention and start with four assumptions as follows:

- That most readers are familiar with three fundamentals of economics, viz;

- That economics considers choice between alternatives or "opportunity cost";

- That economics considers real resources (people, houses, land etc) and only uses currency $(f)$ as a common unit to compare unlike articles, activities, or "goods" and does not wish to be confused with accountancy;

- That discounting is based on a preference for the present over the future or, "a bird in the hand is worth two in the bush".

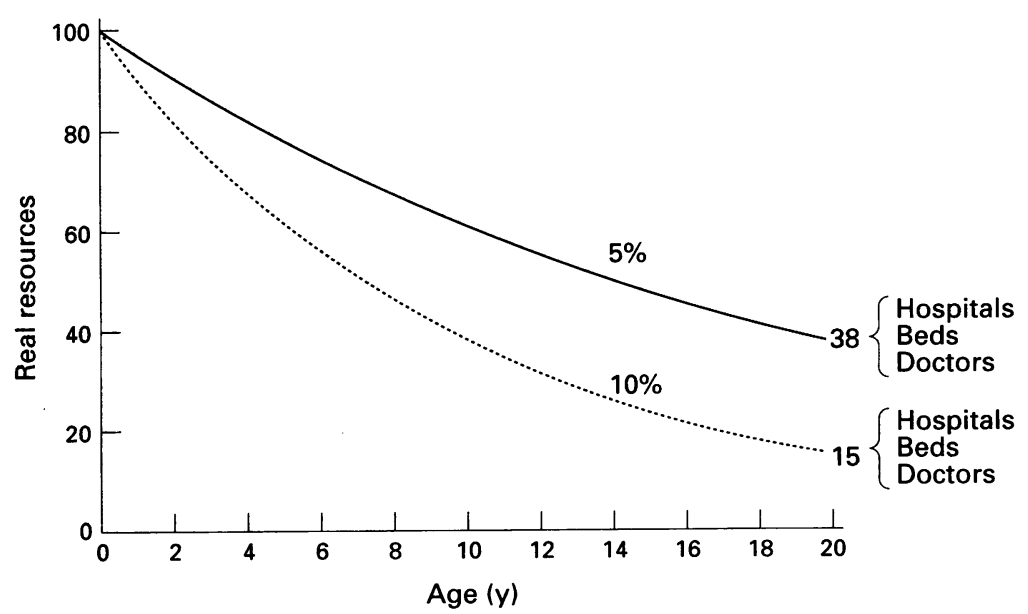

Figure 1 Effect of discounting ... on real resources.

\section{DISCOUNTING}

Conventional economic teaching describes discounting as arising from individuals' preference for the present over the future, assumes that society does likewise, and calls this a "socia time preference". The discount rate (or social rate of discount) is then an expression of average individuals' preference for the present over the future or a mathematical measure of social time preference. Through most of the past 20 years, the period when health economics has grown from infancy to manhood (with a 100 fold increase in the number of articles per annum in English language medical journals), ${ }^{3}$ discounting has been almost inseparable from economics. Doubters, principally non-economists, have been told that they do not understand or that they do not believe; discounting is in effect part of the "creed". Although economists have more recently started to doubt and discuss the foundations of discounting, ${ }^{4}$ the economic consensus strongly advocates the practice ${ }^{5}$ and a strong inertia surrounds, supports, and protects a current consensus paradigm from assaults by deviants and heretics. ${ }^{6-8}$

\section{Origin of discounting}

Discounting may have sociological or anthropological origins illustrated by three comparisons of an individual's valuation now of:

- A meal today - present value one meal, because here and hungry now;

- A meal tomorrow - present value nearly one meal, because probably here and probably hungry tomorrow; and

- A meal next year, present value less than one meal, because maybe not here, not hungry, or may have developed an alternative source of obtaining a meal or of paying for it.

There is an important underlying assumption in such reasoning. It is that the environmen within which the individual moves, chooses, and decides to choose is effectively stable and predictable. The theory of discounting is in effect based on the perceptions of a variable and mobile individual (or group of individuals) within a stable and constant environment (or universe). While the needs and wants of individuals may vary with time or may be time dependent, those of society are far more constant or so constant as to be effectively time independent. ${ }^{9}$ For example, in the UK, 55 million meals are needed just as much in a year's time as today.

Discounting has been applied most consistently to the cost (or investment) side of cost benefit analyses, but it has also been applied to benefits. The distinction is immaterial as the following will show since the economic comparison should be of real "goods" (people, homes, land etc).

\section{The discount rate}

The calculation of a discount rate is simple mathematically. A $5 \%$ discount rate merely means that the present value of an economic good available in one year's time is 5\% less 
than the present value of the same good available here and now. The effects of two discount rates, typical of those used in many health care applications in the past 20 years, are illustrated in figure 1 . While $5 \%$ or even $10 \%$ sounds relatively innocuous over a year, the effect over 20 years is to significantly reduce the value of all economic goods (hospitals, beds, doctors, nurses etc). This is inconsistent with economics' concern for real resources (people, houses, land etc). The real value of these real resources is not so time dependent and does not decay at such rates. Public policy decisions are not of the nature of investing cash now for cash return at some time in the future, but of investing real resources (life years) now for real resources benefit (life years) at some time in the future. Recent discussion of different rates of discount for costs and benefits show the Achilles' heel of the principal of discounting. ${ }^{10-12}$

\section{Estimating individual discount rates}

If both the rationale and the basis of discounting are accepted for the present, the value of a discount rate might be estimated by presenting individuals with either theoretical or real choice. ${ }^{13}$ It is well recognised that individuals choose different rates for different articles, activities, or goods and this has led to the acceptance of differing discount rates for different activities, and even occasionally to consideration of a $0 \%$ discount rate for some activities. It is also well recognised that different individuals choose different rates for the same goods; in particular, for example, that the better off value the future more highly than the less well off. This social class difference in discounting probably has quite a rational basis in that the better off can be more confident that they will live to enjoy the future. Notwithstanding individual variation, enough individual estimates could provide an average individual discount rate or average individual time preference. However, it does not give a societal discount rate or a social time preference. To argue that it should would be fallacious because it would require imputing the values of transient individuals, in a nearly stable or permanent society, on to a nearly stable or permanent society. ${ }^{9}$ While the needs of individuals may vary widely with time, the global needs of the whole of society vary little.

\section{Official discount rate}

During the period of rapid growth in health economics, the recommended discount rate for a study was often explicitly and frankly the discount rate of the previous study in the same area, plus or minus a bit to test sensitivity. ${ }^{5}$ This implied acceptance both that discounting was appropriate and that the previous study discounted at about the right rate. A search for the source or origin reveals that in practice the underlying discount rate for public policy planning is set by the Treasury. An important and fundamental question is what insight the Treasury has over our social time preference, because after all the Treasury is really only a big accountant which adds up departmental claims and allocates shares of public money. Tacit acceptance that the Treasury knows the relative value of the future compared with the present and can rationally choose what rate to discount the future on society's behalf, implies effective abandonment of one of the economists' fundamental principles or assumptions, viz that economics is not accountancy (see above).

Further enquiry reveals that the public sector discount rate is set on business principles by direct comparison with "profit" in commerce. An example of how the Chancellor of the Exchequer revises the rate can be read in Hansard. "Since the use of discount rates in the public sector was last reviewed (in 1978), the rate of return in the private sector has risen to $11 \%$. In light of this the Government has decided to raise the 'required rate of return' in the trading public sector to $8 \%$ in real terms ... and ... the discount rate in the non-trading public sector should be ... not less than $6 \%$ in real terms". ${ }^{14}$ It seems that the thought sequence has been along the following lines. Nationalised industries should be comparable with private industry and should be run along the same lines as private industry to return profits to their shareholders (by proxy, the Government?). Secondly, the non-trading public services, administered according to the same rules by the same civil servants, should return "profits" of a comparable order, because by opportunity cost the shareholders (the Government, on our behalf?) could have been making a real return (profit) in the trading sector instead of providing a service in the non-trading sector. Thirdly, society's social time preference is linked to return on investment and varies from time to time according to short term variation in the financial rate of return in the money market.

\section{Human capital: value of individuals}

Figure 2 illustrates an "economic profile" of an individual life within society. Like most economic diagrams, it is purely symbolic; it is not intended in any way to be ageist, merely to be a stylised representation of an observation. Nor is it sexist (no distinction is made between men and women) or dependent on earnings as a proxy for contribution or consumption. In infancy an individual is entirely dependent, through childhood an individual is mostly a net consumer, through normal adult life most individuals are net contributors, and in retirement individuals become recipients again until in old age some may become fully $d e-$ pendent. Clearly, there would be individual variation and temporal variation around the general curve and so the figure represents no more than a symbolic average profile.

Although symbolic, the figure can help to illustrate the effect of discounting on present values of future "human capital" and a possible logical entry for discounting in health care applications of cost-benefit analysis. The set of figures includes forward projections both without discount (or discounted at $0 \%$ ) and 

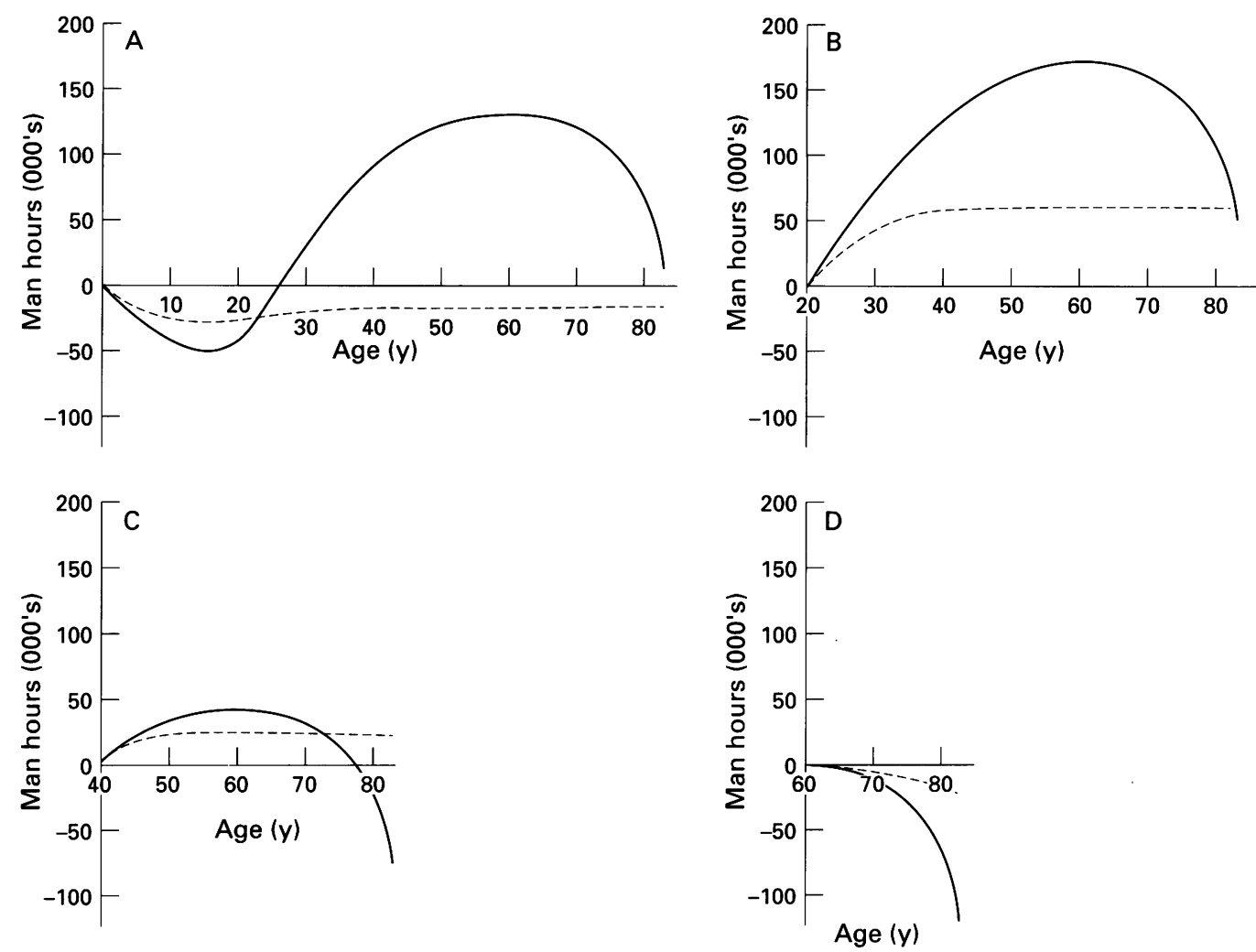

Figure 2 Economic profile of an individual within society, including forward projections without discount $(\longrightarrow$ ) and with $10 \%$ discount (---), (A) from birth, (B) from young adulthood (age 20), (C) from middle age (age 40), and (D) approaching retirement (age 60).

discounted at $10 \%$ per annum from birth, young adulthood (age 20), middle age (age 40 ), and approaching retirement (age 60), since cost-benefit analysis is traditionally indifferent to the past and is concerned only with choice relating to the future. These projections suggest that society stands to gain most by health care programmes directed at keeping young adults well and in harness, because the cost of childhood has been met (fig 2B) and illustrate the inherent bias introduced by cost-benefit analysis. Projections from middle age become more influenced by future costs of retirement, but when discounted the net present value of the foreseeable future may remain positive (fig $2 \mathrm{C}$ ). This provides a logical point of entry of discounting into cost-benefit analysis of health care programmes, to maximise the contribution of the near future and minimise the effect of old age and hence calculate a "positive future". Projections in later life are negative and discounting does not conceal the net consumption (fig 2D). To find "value" in health care for the elderly alternative strategies need to be introduced, like adding "implicit social value" of saving life per se. ${ }^{15}$ Projection from birth (the original curve in fig $2 \mathrm{~A}$ shows early consumption, subsequent contribution, and final consumption. When discounted, the forward projection is dominated by the near future costs of dependency and the net present value remains wholly negative.

\section{Human capital: value of society}

Society comprises many individuals at different points in their individual lifetime trajectories.
A whole society is relatively stable and its population age and sex distribution is relatively constant. In the UK, nearly one fifth of the population is below school leaving age and nearly one fifth is over retirement age. Addition of millions of individual economic profiles (fig 2) yields an overall equilibrium, (or possibly a small net gain, "economic growth"?) As society itself is relatively stable and economic values lie with real goods (people, houses, land etc) the value of society in real terms remains relatively stable and comparisons in real terms between different points in time suggest that next year is as valuable as this. Health care programmes or other public policies that yield a certain number of life years of benefit next year are equally as valuable to society as programmes that yield the same number of life years of benefit now. The economic choice for public policy makers is after all between real goods and not a trade in money. While individuals may prefer present life years to future life years, there is no rationale for society to do so.

\section{Discounting in health care planning}

The consequences of discounting on health care planning might be summarised briefly as follows.

\section{HEALTHY NEWBORN}

Examples of the odd and unacceptable effects of discounting in health care planning abound. Some years ago a cost benefit analysis of screening estimated the (present value) cost at birth 
of eight normal children as $£ 450000$ at 1974 prices. ${ }^{16}$ Such estimates would put the (present value) cost of a standard family of $2 \cdot 2$ at around three quarters of a million pounds at 1995 prices. While parents would accept that rearing a family is a financial burden and that sharing the burden with society with state aid in health care, education, family allowance, and tax concessions reduces the net visible burden on the family, few would estimate the cost so highly. Expressed another way, such estimates imply that the UK goes into the red to the tune of some $£ 75000 \mathrm{M}$ per annum, simply replacing itself. This is, of course, absurd. Clearly something is wrong - the arithmetic, the calculation, the prior assumptions, or the underlying theory. ${ }^{17}$ Although a problem with discounting in screening was recognised by some health economists, it was perceived more as one of the context (screening) than a general problem of discounting.

\section{PAEDIATRICS}

Since the discounter finds normal healthy babies to be an enormous (net present value) cost to parents and society, his arithmetic would show that any additional costs incurred in caring for sick babies would increase this net present cost further. If economists are the "guardians of rationality, ${ }^{18}$ the rational discounter would find most of paediatrics unjustifiable. This does not accord with experience in health care or the wishes of society; individually and collectively, sick babies can attract enormous financial support and society values paediatrics very highly.

\section{SCREENING}

Screening seeks by present activity to reduce the likelihood of disease and hence cost of care at some time in the future. While the principal economic issue in screening is inefficiency, when the condition being sought is rare (as in the example of mass miniature radiography for tuberculosis in the 1970s), cost-benefit analysis of screening programmes and decisions on whether or not to screen depend highly on discount rate since present costs are incurred in the hope of achieving future benefit. Again the rational discounter would have to drop most screening programmes, particularly those for late onset disease (for example the cancers and heart disease), which is hardly what public health advocates.

\section{HEALTH EDUCATION}

Health education has been focused strongly on long term health gains (for example cigarette smoking and lung cancer) and its message has been more widely heeded by upper social classes than by lower social classes. The rational discounter would undervalue future benefits of health education as does social class V. Again, this does not reflect the perceived wisdom of modern public health policy with an ever increasing emphasis on health education and continuing development of programmers to instill middle class (or social class II) values on the disadvantaged. ${ }^{1920}$ Perhaps health education would have greater impact on individuals if the message focused more strongly on short term benefit (for example, cigarette smoking and athletic prowess).

OCCUPATIONAL AND ENVIRONMENTAL MEDICINE In developed countries, much of the emphasis of occupational and environmental medicine is on chronic disease, often of late onset and with long latent periods. The rational discounter would underestimate the significance of future cancers in old age (when the individual is no longer economically active) that might arise as a consequence of current working practices or poor pollution control, and might recommend that occupational and environmental medicine restrict its interest to the short term. This is hardly what we have come to expect from organisations like the Health and Safety Executive, which together with kindred bodies are continually reviewing and lowering threshold limit values. ${ }^{21-23}$

\section{Theory does not satisfactorily explain observations}

The above examples suggest that discounted forward projections (in fig 2) give a sensible answer, an answer that accords with social values and societal choice, only in young adulthood and early middle age. It seems that the arithmetic (or discount rate) is wrong at least in some applications or alternatively that the principle of discounting is wrong. ${ }^{9}$ A theory provides a more satisfactory explanation of observations and is more acceptable when it is robust and widely or generally applicable. Discounting is not so satisfactory if it works in some circumstances only. It also seems that society's valuation of individual lives is not only determined in the future but recognises the contributions of whole lives and this should be incorporated into cost-benefit analysis. ${ }^{9}$

After several years of rather blind implementation of economic techniques including discounting in public policy making and planning, despite some appreciation of the weaknesses of neoclassical economic theory and its inability to explain satisfactorily the world of health care, ${ }^{18}$ we are now witnessing some encouraging hints of economists challenging the assumptions underlying several of these economic practices. ${ }^{10-12}$ In particular, in health care it has been observed that the conventional practice of discounting all health programmes may not reflect individual or societal preference. In science, when theory fails to fit the facts (or the observations) a new theory is born, as for example in physics at the turn of the century when there was a move from the wave theory of light to the quantum theory to explain a new set of observed phenomena. If neoclassical economics has difficulty understanding and explaining a major social phenomena like health and wishes to do so, it needs to rethink its theory. Perhaps it is time for neoclassical economics to be replaced by 
"quantum" economics, if "small is beautiful". Evolution in science takes time: eminent philosophers have observed how consensus defends and protects one established theory from challenges by potential replacements until a threshold is breached and suddenly there is revolution and a new theory becomes the preferred theory. ${ }^{67}$ Economics has been described as an evolutionary science that changes to suit shifting trends in society ${ }^{1}$ and so it is perhaps time for economic theory to consider a revolution on the principal of discounting the future in collective policy issues. $^{24}$

\section{Time for change on discounting}

It is time for a change in economic thinking. The theories do not fit the observations and the formulae do not accord with society's choices. ${ }^{25}$ In particular, the theory of discounting in health care does not satisfactorily explain society's preference and choices in health care. Under the repeatedly exhorted philosophy to "live now, and pay later", society will indeed pay later and the real cost, not an artificially discounted present value estimate, will have to be met in real terms. For example in health care, the elderly in the community will need to be cared for (by the elderly in the community?). The rationale for not discounting in health care and in other collective societal policy decisions lies with the following:

- Payment now is in real terms (life years) and not in cash (economics is not accountancy);

- Real goods (life years) do not lose value because society is not ageing (the needs of society in the future are nearly the needs of society now);

- Society's values are not simply the addition of many individuals' values.

Important lessons could be learned from examining history. The dominant current philosophy of seeking a high rate of return on investment and of heavily discounting the future or even worse making money by speculating, arbitraging currency, and playing interest rate differentials rather than investing in real factories, employing real workers and producing real products, ${ }^{26}$ was not the philosophy of our forebears. Contemporary society still lives off real capital left by previous generations. For example, bridges built in the middle ages for pack horses, which a discount rate of only $0.5 \%$ would have written off many years ago, still stand under loads of 38 tonne lorries. In 1920 Pigou wrote that it was "a clear duty of Government ... as trustee for unborn generations as well as its present citizens ... to defend exhaustible natural resources ... from reckless spoilation" ${ }^{27}$ The most important natural resource (economic good?) is people, and people in the future are as valuable to society as people now. The sooner we learn to drop the whole concept of discounting the future (or set a $0 \%$ discount rate) for health care planning and other public policy decisions, the better for the future of collective decision making and of society generally.

1 Samuelson P, Nordhaus W. Economics. McGraw Hill: New York, 1985.

2 Mooney GH, Drummond MF. What is economics? (in six parts). BMF 1982;285:949; 1983;286:41.

3 Elixhauser A, Luke BR, Taylor WR, Rebland J. Health care CBA/CEA: an update on the growth and composition of the literature. Med Care 1993;31:JS 1-11.

4 Lind RC ed. Discounting for time and risk in energy policy. Washington DC: Resources for the future, 1982

5 Drummond MF, Stoddart GT, Torrance GL. Principles of economic appraisal in health care. Oxford, 1980.

6 Kuhn TS. Structure of scientific revolutions. Chicago: University of Chicago Press, 1962.

7 Medawar PB. Induction and interaction in scientific thought. London: Methuen, 1970.

8 Popper K. Objective knowledge: an evolutionary approach. London: Oxford University Press, 1972.

9 West RR. Valuation of life in long run health care programmes. $B M \mathcal{F}$ 1985;291:1139-41.

10 Parsonage $M$, Neuberger H. Discounting and QALYs. Heath Economics 1992;i:71-9.

11 Sheldon TA. Discounting in health care decision-making time for a change? $\mathcal{F}$ Public Health Med 1992;14:250-6.

12 Krahn M, Gafni A. Discounting in the economic evaluation of health care interventions. Med Care 1993;31:403-18.

13 Feldstein MS. The social time preference discount rate in cost benefit analysis. The Economic fournal 1964:360-79.

14 Chancellor of the Exchequer. Required rate of return and discount rates in the public sector. Hansard. House of Commons debates 1988-9. 150 written answers col. 187 .

15 Buxton MJ, West RR. Cost-benefit analysis of long-term haemodialysis for chronic renal failure. BMF 1975; ii:3769.

16 Hagard S, Carter FA. Preventing the birth of infants' with Down's syndrome: a cost benefit analysis. $B M \mathcal{F} 1976$; 753-6.

17 West RR. Screening for Down's syndrome or 'preventing the birth of infants: a cost analysis?'. BMF 1976;i:1278-9.

18 McGuire A, Henderson J, Mooney G. The economics of health care: an introductory text. London: Routledge Kegan Paul, 1987.

19 Department of Health and Social Security. Prevention and health: everybody's business. London: HMSO, 1976.

20 Smith A, Jacobson B. The Nation's health: a strategy for the 1990s. London: King's Fund, 1989.

21 International Labour Office. Control and prevention of occupational hazards caused by carcinogenic substances and agents. Geneva: ILO, 1974 .

22 Health and Safety Executive. Control of substances hazardous to health: draft regulations and codes of practice. London: HMSO, 1984.

23 American Conference of Governmental Industrial $\mathrm{Hy}$ gienists. Threshold limit values and biological exposure indices. Cincinnati: ACGIH, 1987

24 Schumacher EF. Small is beautiful: a study of economics as if people mattered. London: Blond and Briggs, 1973.

25 Omerod P. Death of economics. London: Faber and Faber 1994.

26 Henderson $\mathrm{H}$. The policies of the solar age: alternative to economics. New York: Doubleday, 1981.

27 Pigou AC. The economics of welfare. London: Macmillan, 1920 